ORIGINAL ARTICLE

\title{
Burden of influenza in healthy children and their households
}

\author{
N Principi, S Esposito, R Gasparini, P Marchisio, P Crovari, for the Flu-Flu Study Group*
}

Arch Dis Child 2004;89:1002-1007. doi: 10.1136/adc.2003.045401

See end of article for authors' affiliations

....................

Correspondence to: Nicola Principi, Institute of Paediatrics, University of Milan, Via Commenda 9, 20122 Milan, Italy; Nicola.Principi@unimi.it

Revised version received 12 April 2004

Accepted for publication 14 April 2004

\begin{abstract}
Objective: A prospective, multicentre study was conducted to evaluate the burden of laboratory confirmed influenza in healthy children and their household contacts.

Methods: The patients were enrolled in four emergency departments (EDs) and by five primary care paediatricians (PCPs) in different Italian municipalities 2 days a week between November 1, 2001 and April 30, 2002. The study involved 3771 children less than 14 years of age with no chronic medical conditions who presented with a respiratory tract infection in EDs or PCP outpatient clinics during the study period. Nasopharyngeal swabs were collected for the isolation of influenza viruses and RNA detection. Information was also collected concerning respiratory illnesses and related morbidities among the study children and their household contacts.

Results: Influenza virus was demonstrated in 352 cases (9.3\%). In comparison with the influenza negative children, those who were influenza positive had an older mean age, were more often attending day care centres or schools, more frequently experienced fever and croup, received more antipyretics, and had a longer duration of fever and school absence. Furthermore, their parents and siblings had more respiratory illnesses, received more antipyretics and antibiotics, needed more medical visits, missed more work or school days, and needed help at home to care for the ill children for a longer period of time.

Conclusions: Influenza has a significant clinical and socioeconomic impact on healthy children and their families. Prevention strategies should also focus on healthy children regardless of their age because of their role in disease transmission.
\end{abstract}

\section{$\mathrm{U}$} ntil the end of the last century, influenza was considered a serious illness only in the elderly and people of any age with certain chronic medical conditions leading to an increased risk of complications. ${ }^{1-3}$ For this reason, influenza vaccination was recommended only in subjects more than 64 years of age and in children as well as adults with high risk medical conditions. ${ }^{45}$

However, it has recently been demonstrated that, during influenza periods, healthy children less than 2 years of age had a significantly greater risk of hospitalisation for acute respiratory disease than older healthy children and a risk similar to that of children 5-15 years of age with high risk medical conditions. ${ }^{6}$ Moreover, other studies have shown excess numbers of outpatient visits and antibiotic prescriptions among healthy day care and school aged children. ${ }^{7-9}$ Finally, several reports have shown that children are the major route of transmission of influenza viruses to household contacts, thus highlighting the potential of influenza to affect the quality of life of children and their families. ${ }^{10-13}$

Recent findings on the impact of influenza in healthy children have led the US Advisory Committee on Immunization Practices to encourage influenza vaccination in all subjects aged 6-23 months. ${ }^{14}$ However, the interpretation of many studies is confounded by the lack of laboratory confirmation of influenza-like illnesses, the co-circulation of respiratory syncytial viruses, and the fact that they are retrospective..$^{6-8}$ Furthermore, the impact of influenza may vary from year to year, and be influenced by circulating strains and protective antibody levels in the population. ${ }^{14}$ Consequently, further virological and epidemiological data evaluating the global health of children and economic burden of influenza in healthy children are needed to define the best strategies for influenza prevention in paediatric subjects. This prospective study was designed to evaluate the burden of laboratory confirmed influenza in healthy children and their households.

\section{METHODS}

\section{Study design}

This was a prospective, multicentre study of children with respiratory tract infections in Italy. The patients were enrolled in four emergency departments (EDs) and by five primary care paediatricians (PCPs) in different Italian municipalities between November 1, 2001 and April 30, 2002. The EDs were located in Milan, Genoa, Florence, and Naples, and the PCP clinics in Milan and Genoa. Most of the children enrolled in EDs were taken to the hospital directly by their parents and were not referred by PCPs. The study protocol was approved by the Institutional Review Board of each centre.

\section{Study population}

During the study period, we enrolled all subjects younger than 14 years of age without chronic medical conditions presenting on 2 days of the week (Wednesday and Sunday in EDs or Tuesday and Thursday in PCP clinics) with signs and/ or symptoms of respiratory tract infection, diagnosed as the presence of at least one of the following symptoms: runny nose, nasal congestion, sore throat, cough, earache, wheezing, and/or shortness of breath, regardless of fever (defined as an axillary temperature $\geqslant 38^{\circ} \mathrm{C}$ ). ${ }^{15}$ The exclusion criteria included concomitant chronic diseases at increased risk for influenza complications. ${ }^{1-3}$ Only one child per family was included in the study. Written informed consent of a parent or legal guardian was required, and the older children were asked for their assent. There were no refusals to participate.

\section{Enrolment and evaluation of patients}

Upon enrolment, systematic recordings were made of the patients' demographic characteristics and medical history using standardised written questionnaires. The questions

Abbreviations: $E D$, emergency department; $P C P$, primary care paediatrician; $\mathrm{PCR}$, polymerase chain reaction; RT, reverse transcription; $\mathrm{RTI}$, respiratory tract infection 
included: detailed signs and symptoms of the acute episode of respiratory tract infection; laboratory and/or radiological examinations; prescribed drug therapy; previous administration of influenza vaccine; family size and number of siblings; parents' education and occupation; family living conditions; and information about child care attendance. After a complete physical examination, the children were classified into six disease groups based on well established criteria ${ }^{16}$ : common cold, pharyngitis, acute otitis media, croup, acute bronchitis, and pneumonia. When signs and symptoms of more than one disease were present, children were classified in the more severe disease group. The diagnosis of acute otitis media was performed with pneumatic otoscopy and the diagnosis of pneumonia with chest radiograph.

Nasopharyngeal samples were collected at enrolment by Virocult swab (Medical Wire and Equipment, Corsham, UK) to obtain specimens for influenza virus isolation and RNA detection. The samples were immediately sent by courier to a central laboratory (Department of Health Sciences, University of Genoa, Genoa), where they were divided into two fractions: one was inoculated into MDCK cells for isolation and the other was used for detection, typing, and subtyping by gene amplification as previously described ${ }^{17-20}$ The isolated strains were further identified by a haemoagglutination inhibition test using ferret post-infection sera at the WHO Influenza Centre, London, UK. Viral RNA was extracted using QIA techniques according to the manufacturer's instructions (RNeasy Minikit, Qiagen, Valencia, CA). Reverse transcription (RT) and polymerase chain reaction (PCR) were performed using standard methodologies. ${ }^{18-20}$

The medical history of the children was re-evaluated 57 days after enrolment and until the resolution of their illness by means of interviews and clinical examination by trained investigators using standardised questionnaires. During this evaluation, information regarding respiratory illnesses and related morbidity among households was also obtained. Parents or legal guardians were asked to answer a list of questions regarding the outcome of the disease in their children (for example, final diagnosis, administered medication, hospitalisation, duration of signs/symptoms of the illness, medical visits, examinations, number of school days lost) and the involvement of other family members (for example, respiratory diseases in household contacts, medication, hospitalisation, medical visits, number of work days lost by parents to care for their ill children and their own respiratory diseases, number of days of domestic help required to care for ill children). All data of the study children and their households were verified from medical records.

\section{Statistical analysis}

The data of all patients were analysed using SAS for Windows v. 12 (SAS Institute, Cary, NC, USA), and comparisons made between influenza positive and influenza negative cases, influenza positive children enrolled in EDs and by PCPs, influenza A and influenza B cases, and influenza positive children by age $(<2$ years, $2-5$ years, $>5$ years). A p value of $<0.05$ was considered statistically significant for all tests. Parametric data were compared using analysis of variance (ANOVA); abnormally distributed or non-parametric data were analysed using the Kruskal-Wallis test. Categorical data were analysed using contingency analysis and the $\chi^{2}$ or Fisher's test.

\section{RESULTS}

\section{Epidemiology}

The study included 3771 children younger than 14 years of age (1990 males; median age: 2.5 years), 2970 (78.8\%) enrolled in EDs, and $801(21.2 \%)$ by PCPs. Influenza virus was demonstrated in 352 cases (9.3\%): 260/2970 (8.7\%) children enrolled in EDs and 92/801 (11.5\%) enrolled by PCPs $(\mathrm{p}=0.022)$. Influenza A viruses were identified in 183 cases (52.0\%: $129 \mathrm{H} 3 \mathrm{~N} 2,70.5 \%$; $54 \mathrm{H} 1 \mathrm{N1}, 29.5 \%$ ) and influenza B virus in $169(48.0 \%)$. In all cases, influenza viruses were detected by PCR and in 319/352 (90.6\%) samples isolation of influenza viruses was also obtained. No significant difference was observed in the epidemiology of influenza infection in the different municipalities.

Figure 1 shows the distribution of influenza positive swabs. Considering all the influenza viruses together, the peak incidence of positive cases (at least $10 \%$ of the total number of positive influenza virus tests) was between the 3rd and 10th weeks of 2002, the highest incidence occurring in the 7 th week (17.4\% in EDs and $35.3 \%$ in PCP clinics) $(\mathrm{p}=0.019)$. Influenza $\mathrm{B}$ virus circulated earlier than influenza A viruses, peaking between the 3rd and 7th weeks of 2002 versus the 8 th and 10th weeks.

\section{Characteristics of the study patients}

Table 1 shows the general characteristics of the influenza positive and influenza negative children; the only significant difference was median age, which was higher in the influenza positive children. However, as there were 109, 167 , and 76 cases of influenza A and B in children $<2$ years, $2-5$ years, and $>5$ years of age, respectively, $78.4 \%$ of all influenza cases were in children younger than 5 years of age.

The influenza positive children seen by PCPs had a significantly older mean (SD) age than those enrolled in EDs (5.48 (3.38) v 3.43 (2.56) years, $\mathrm{p}<0.0001)$, and were significantly more frequently affected by influenza B infections $(52 / 801,6.5 \% v 117 / 2970,3.9 \%, p=0.002)$. Influenza A cases were equally distributed in the different age groups ( $<2$ years, $2-5$ years, $>5$ years), whereas the influenza $\mathrm{B}$ cases had a significantly older mean age than the influenza A cases (4.81 (3.24) v 3.19 (2.38) years, $\mathrm{p}<0.0001$ ) (fig 2). There were no other significant differences in the general characteristics of the children enrolled in EDs or by PCPs, or between influenza A and influenza B positive subjects.

Table 2 shows the data on clinical presentation, the diagnostic methods used at enrolment, therapeutic approaches, and clinical outcomes.

The clinical presentation of respiratory tract infection was similar among the influenza positive and influenza negative children, but fever and croup were significantly more frequent among the former, and acute otitis media was significantly more frequent among the latter. Croup was significantly more frequent in the influenza positive children enrolled by PCPs than in those enrolled in EDs (36/92, 39.1\% $v 16 / 260,6.1 \%, \mathrm{p}<0.0001)$, but there was no other significant between group difference. The children with influenza B virus had croup significantly more frequently and pharyngitis significantly less frequently than those with influenza A viruses $(35 / 169,20.7 \% \vee 17 / 183,9.2 \%, \mathrm{p}=0.004$, and $69 / 169$, $40.8 \% \vee 99 / 183,54.0 \%, \mathrm{p}=0.017)$; no other significant differences were detected. The influenza positive patients aged $<2$ years had fever at any time during influenza illness significantly less frequently than those aged $2-5$ years $(88 /$ $109,80.7 \% v 155 / 167,92.8 \%, \mathrm{p}=0.004)$ or $>5$ years $(88 / 109$, $80.7 \% \vee 72 / 76,94.7 \%, \mathrm{p}=0.011)$; no other age related differences were observed.

The diagnostic methods used at enrolment were similar in influenza positive and influenza negative children, influenza positive children enrolled in EDs or by PCPs, influenza A and B cases, and influenza positive children of different ages.

In terms of therapy, the influenza positive children received antipyretics significantly more often and for longer periods than their negative counterparts, whereas there was no significant difference in antibiotic prescription and use. 


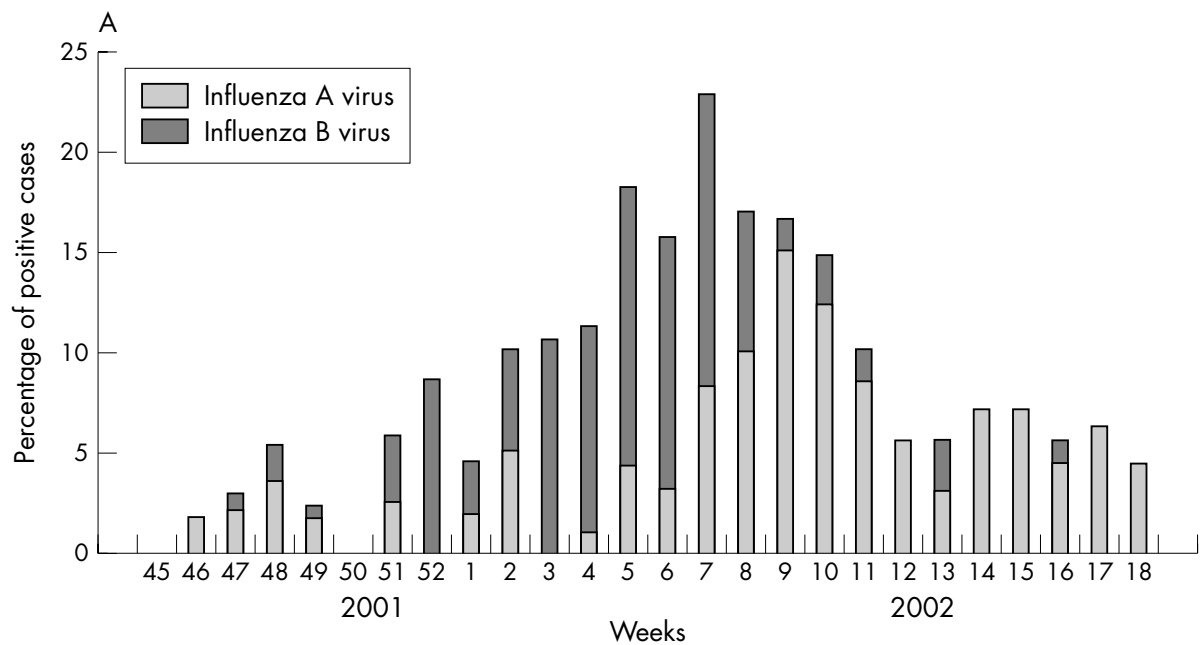

Figure 1 Distribution of laboratory diagnosis of influenza expressed as a percentage of influenza $A$ and influenza $B$ cases diagnosed in the 3771 study children with acute respiratory tract infections without chronic medical conditions enrolled between November 1, 2001 and April 30,2002 , in four Italian municipalities (panel A). The distribution of influenza cases expressed as a percentage of acute respiratory tract infections diagnosed in the 2970 subjects enrolled in EDs and the 801 seen by PCPs is also shown (panel B).

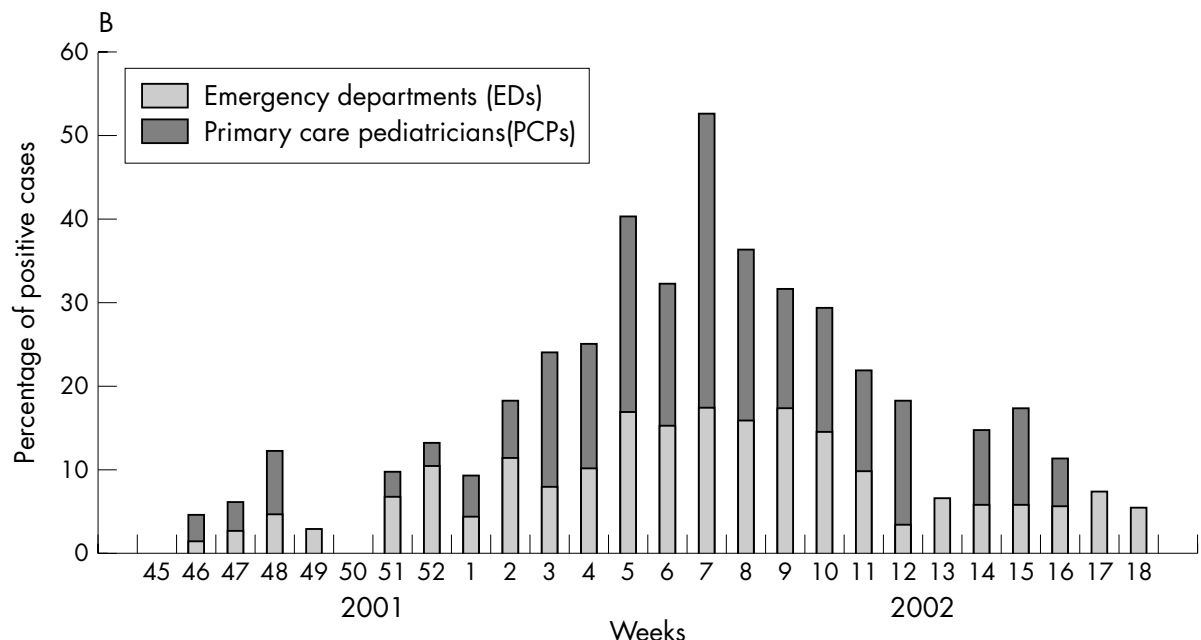

Despite the international campaign for control of injudicious antibiotic use, antibiotic prescriptions were dispensed for more than $50 \%$ of the children in both the groups. Antiviral agents were not used in any case. No difference in medication usage was observed between the influenza positive children enrolled in EDs or by PCPs, or between influenza A and

Table 1 General characteristics of the study children by influenza diagnosis

\begin{tabular}{|c|c|c|}
\hline & \multicolumn{2}{|l|}{ Influenza diagnosis } \\
\hline & Positive ( $n=352$ ) & Negative $(n=3419)$ \\
\hline Gender, male (\%) & $185(52.5)$ & $1740(50.9)$ \\
\hline Median age (interquartile range), years & $3.20(2.00-8.50)^{*}$ & $2.50(1.40-7.40)$ \\
\hline Vaccinated against influenza (\%) & $7(2.0)$ & $100(2.9)$ \\
\hline Mean family size & 3.60 & 3.67 \\
\hline No. of household contacts (total) & 915 & 9128 \\
\hline No. of parents (total) & 704 & 6838 \\
\hline No. of siblings (total) & 211 & 2290 \\
\hline Working mothers (\%) & $310 / 352(88.1)$ & $2940 / 3419$ (85.9) \\
\hline Working fathers $(\%)$ & $352 / 352(100.0)$ & $3419 / 3419(100.0)$ \\
\hline Household contacts vaccinated against influenza (\%) & $44 / 915(4.8)$ & $543 / 9128(5.9)$ \\
\hline Mean number of rooms in the home & 3.05 & 3.19 \\
\hline Exposure to passive smoking (\%) & $119(33.8)$ & $1122(32.8)$ \\
\hline Full time child care attendance† (\%) & $310(88.1)$ & $2906(85.0)$ \\
\hline Mean (SD) number of RTls in the previous 6 months & $1.43(1.71)$ & $1.64(1.86)$ \\
\hline $\begin{array}{l}\text { Mean (SD) number of antibiotic courses in the } \\
\text { previous } 6 \text { months }\end{array}$ & $0.58(0.98)$ & $0.68(1.23)$ \\
\hline $\begin{array}{l}\text { Mean (SD) number of hospitalisations in the } \\
\text { previous } 3 \text { months }\end{array}$ & $0.02(0.16)$ & $0.03(0.17)$ \\
\hline
\end{tabular}

${ }^{*} \mathrm{p}<0.0001 v$ influenza negative children; no other statistically significant differences. †5-6 days/week, 6-8 hours/day.

RTIs, respiratory tract infections. 


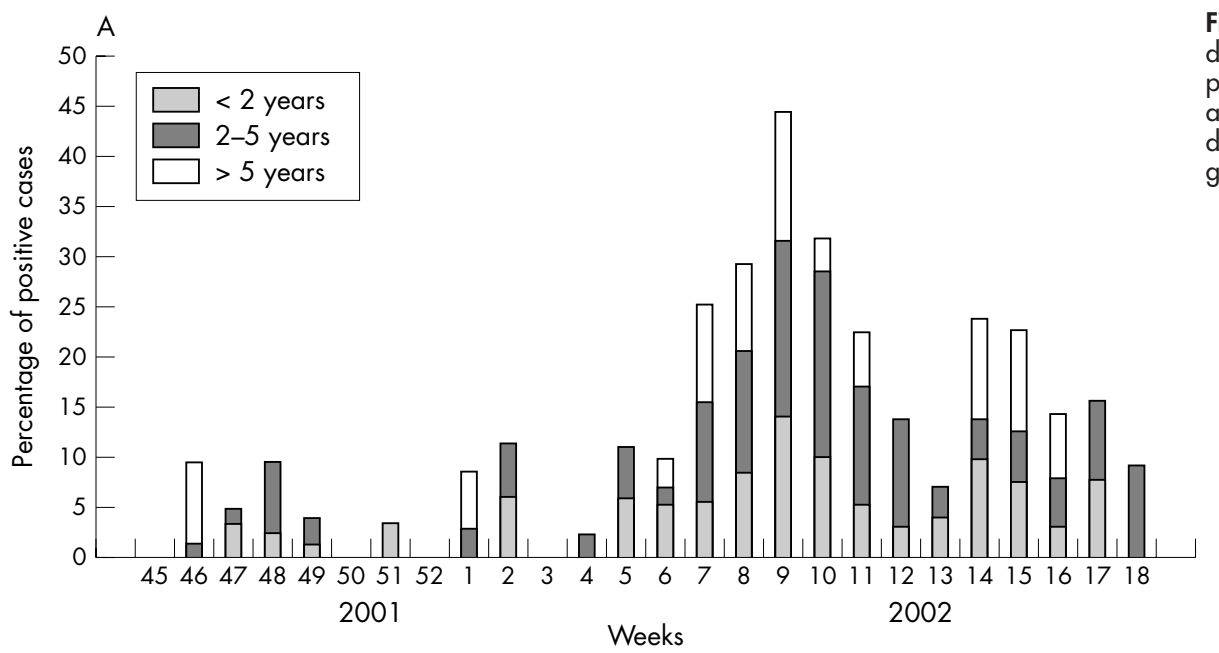

Figure 2 Distribution of laboratory diagnosis of influenza expressed as a percentage of influenza $A$ (panel $A$ ) and influenza $B$ (panel B) cases diagnosed in children in different age groups.

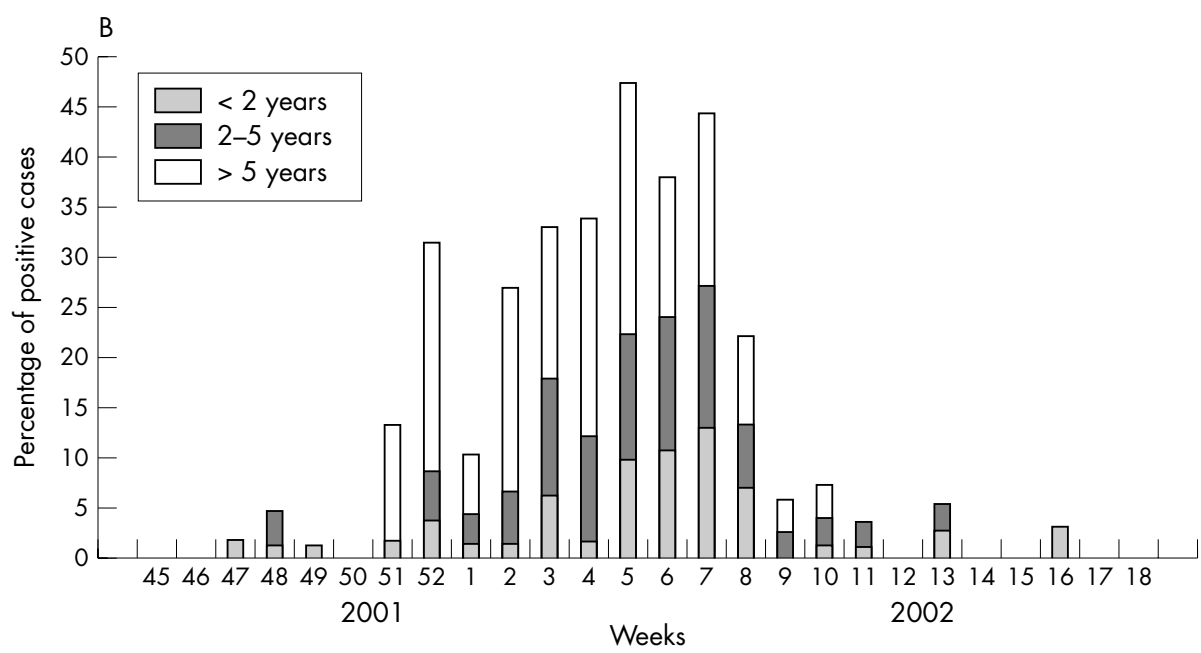

influenza B cases. The influenza positive children aged $<2$ years were prescribed antipyretics significantly less frequently than the children aged $2-5$ years $(73 / 109,66.9 \%$ $v 133 / 167,80.8 \%, \mathrm{p}=0.026)$ or $>5$ years $(63 / 76,80.3 \%$, $\mathrm{p}=0.024)$; no other age related differences were observed.

The influenza positive children had a longer duration of fever and school absence (evaluated among children with full time child care attendance) than the influenza negative children, whereas the prevalence of hospitalisation, its duration, and the number of additional medical visits were similar. No significant differences were observed between the influenza positive children enrolled in EDs or by PCPs, between influenza A and influenza B cases, or between the different age groups.

Socioeconomic effect of influenza among households Table 3 shows that the households of the influenza positive children had significantly more respiratory tract infections than those of the influenza negative children, received significantly more antipyretics and antibiotics, needed significantly more medical visits, missed significantly more work or school days, and needed significantly more help at home to care for ill children.

No significant differences in socioeconomic impact were observed between the households of influenza positive children enrolled in EDs or by PCPs. Home help to care for ill children was required for a significantly longer time in influenza B than in influenza A cases ( 1.30 (2.35) days $v 0.77$
(1.82) days, $p=0.0016$ ). No other significant between group difference was found.

\section{DISCUSSION}

To the best of our knowledge, this is the first prospective study simultaneously evaluating the effect of laboratory confirmed influenza on healthy children and their household contacts, comparing influenza infection in different paediatric practice settings, analysing differences between influenza A and influenza B in a large group of children, and studying the age related characteristics of influenza infection. The main findings seem to be those indicating the substantial impact of influenza on healthy children and their families. Like previous studies, ${ }^{21-24}$ we found that healthy children attending day care and school are the most frequently affected by influenza and their illness is often associated with a high disease burden in families.

The fact that influenza in healthy children can cause relevant social problems is shown by the observation that our influenza positive children missed significantly more school days than those with respiratory disease due to different pathogens. These data support the wider paediatric use of influenza vaccination and suggest that the current recommendation from the United States encouraging the use of influenza vaccination in healthy children aged $<2$ years ${ }^{14}$ should be extended to older children.

The socioeconomic impact of influenza in healthy children on household contacts, which seems to be significantly 


\begin{tabular}{|c|c|c|}
\hline & \multicolumn{2}{|c|}{ Influenza diagnosis } \\
\hline & $\begin{array}{l}\text { Positive } \\
\text { ( } n=352 \text { ) }\end{array}$ & $\begin{array}{l}\text { Negative } \\
(\mathrm{n}=3419)\end{array}$ \\
\hline \multicolumn{3}{|l|}{ Clinical presentation } \\
\hline Axillary temperature $\geqslant 38^{\circ} \mathrm{C}(\%)$ & $315(89.4)^{*}$ & $2393(70.0)$ \\
\hline Common cold (\%) & $51(14.4)$ & $463(13.5)$ \\
\hline Pharyngitis (\%) & $168(47.7)$ & $1537(44.9)$ \\
\hline Acute otitis media (\%) & $37(10.5) \dagger$ & $514(15.0)$ \\
\hline Croup (\%) & $52(14.7)^{*}$ & $273(8.0)$ \\
\hline Acute bronchitis (\%) & $22(6.2)$ & $307(8.9)$ \\
\hline Wheezing (\%) & $11(3.1)$ & $189(5.5)$ \\
\hline Pneumonia (\%) & $11(3.1)$ & $136(4.0)$ \\
\hline \multicolumn{3}{|l|}{ Diagnostic methods } \\
\hline Routine blood examinations (\%) & $30(8.5)$ & $307(8.9)$ \\
\hline Microbiological tests (\%) & $15(4.2)$ & $170(4.9)$ \\
\hline Chest radiography (\%) & $15(4.2)$ & $211(6.2)$ \\
\hline \multicolumn{3}{|l|}{ Therapeutic approaches } \\
\hline Antipyretic prescriptions (\%) & $269(76.4)^{*}$ & $2051(59.9)$ \\
\hline Antipyretic use, mean (SD) days & $3.23(1.44)^{*}$ & $2.81(1.45)$ \\
\hline Antibiotic prescriptions $(\%)$ & $193(54.8)$ & $1948(56.9)$ \\
\hline Antibiotic use, mean (SD) days & $7.72(2.47)$ & $7.71(2.45)$ \\
\hline \multicolumn{3}{|l|}{ Clinical outcome } \\
\hline Hospitalisation (\%) & $19(3.9)$ & $173(5.1)$ \\
\hline $\begin{array}{l}\text { Duration of hospitalisation, mean } \\
\text { (SD) days }\end{array}$ & $4.08(1.61)$ & $4.67(2.16)$ \\
\hline $\begin{array}{l}\text { Duration of fever, mean (SD) days } \\
\text { Additional medical visits, mean } \\
\text { (SD) number }\end{array}$ & $\begin{array}{l}3.03(1.85)^{*} \\
0.68(1.23)\end{array}$ & $\begin{array}{l}2.12(1.78) \\
0.66(1.01)\end{array}$ \\
\hline School absence, mean (SD) days & $5.10(2.55)^{*}$ & $4.25(2.93)$ \\
\hline
\end{tabular}

greater than that due to other respiratory infections, is demonstrated by the fact that the parents and siblings of our influenza positive children fell ill significantly more frequently than those living with children suffering from respiratory diseases of different etiology, received more antibiotic and antipyretic prescriptions, and required more medical visits. They were also more frequently absent from work or school and required home help for a longer time to care for ill children. These findings extend some previously published data, ${ }^{152526}$ and indicate that influenza in healthy children considerably affects their families, thus suggesting that influenza prevention may have a significant household impact.

The importance of influenza in paediatric practice is highlighted by the number of peak period visits to EDs and PCP clinics for respiratory diseases due to influenza viruses, with only marginal differences between the two settings. Although in our study children were enrolled during only 2 days per week, the long duration of the study period strengthens our conclusions. Moreover, the considerable influenza related medical burden even in otherwise healthy children is confirmed by the high rate of hospitalisation among our laboratory confirmed cases, regardless of age. Although no other viruses were detected, it is probable that a significant number of the influenza negative cases were due to respiratory syncytial virus (whose epidemiology in Italy is similar to that of influenza viruses), which is the most frequent cause of hospitalisations in the first years of life. ${ }^{27-29}$ Furthermore, most of our hospitalised influenza positive children suffered from lobar pneumonia, thus underlining the possible role of influenza viruses in predisposing healthy subjects to serious diseases and possible bacterial superinfections. $^{3031}$

Our data also add further information concerning the clinical picture of paediatric influenza. We confirm that fever is a major component of influenza presentation, ${ }^{13} 3233$ as it
Table 3 Clinical and socioeconomic impact of influenza among the household contacts of the study children

\begin{tabular}{|c|c|c|}
\hline & \multicolumn{2}{|c|}{$\begin{array}{l}\text { Household contacts of children with } \\
\text { influenza diagnosis }\end{array}$} \\
\hline & $\begin{array}{l}\text { Positive } \\
\text { (n=915) }\end{array}$ & $\begin{array}{l}\text { Negative } \\
(n=9128)\end{array}$ \\
\hline $\begin{array}{l}\text { Similar disease in family } \\
\text { contacts (\%) }\end{array}$ & $138(15.1)^{*}$ & $863(9.5)$ \\
\hline Parents (\%) & $96 / 704(13.6)^{*}$ & $544 / 6838(7.9)$ \\
\hline Siblings (\%) & $42 / 211(19.9)^{*}$ & $319 / 2290(13.9)$ \\
\hline Antipyretic prescriptions (\%) & $123(13.4)^{*}$ & $610(6.7)$ \\
\hline Parents $(\%)$ & $69 / 704(9.8)^{*}$ & $310 / 6838(4.5)$ \\
\hline Siblings (\%) & $54 / 211(25.6)^{*}$ & $300 / 2290(13.1)$ \\
\hline Antibiotic prescriptions (\%) & $73(7.9)^{*}$ & $301(3.3)$ \\
\hline Parents (\%) & $36 / 704(5.1) \dagger$ & $182 / 6838(2.7)$ \\
\hline Siblings (\%) & $37 / 211(17.5)^{*}$ & $119 / 2290(5.2)$ \\
\hline Hospitalisation (\%) & $3(0.3)$ & $11(0.1)$ \\
\hline Parents (\%) & $2 / 704(0.3)$ & $7 / 6838(0.1)$ \\
\hline Siblings (\%) & $1 / 211(0.5)$ & $4 / 2290(0.2)$ \\
\hline $\begin{array}{l}\text { Additional medical visits, } \\
\text { mean (SD) number }\end{array}$ & $0.39(0.76)^{*}$ & $0.14(0.47)$ \\
\hline Parents (\%) & $0.28(0.55)^{\star}$ & $0.07(0.25)$ \\
\hline Siblings (\%) & $0.48(0.98)^{*}$ & $0.22(0.73)$ \\
\hline \multicolumn{3}{|l|}{$\begin{array}{l}\text { Lost work days (parents), } \\
\text { mean (SD) }\end{array}$} \\
\hline For their own illness & $1.52(3.19)^{*}$ & $0.72(2.14)$ \\
\hline For child's illness & $1.25(2.99)^{*}$ & $0.59(2.02)$ \\
\hline $\begin{array}{l}\text { Lost school days (siblings), } \\
\text { mean (SD) }\end{array}$ & $1.27(2.47)^{*}$ & $0.49(2.33)$ \\
\hline $\begin{array}{l}\text { Need for help to care for the } \\
\text { ill children, mean days (SD) }\end{array}$ & $1.10(1.76)^{*}$ & $0.85(1.63)$ \\
\hline
\end{tabular}

was more frequent in our influenza positive children than in those with respiratory diseases due to other agents. However, our findings also show that this sign may be absent in children aged $<2$ years, who are at higher risk for influenza related complications. This suggests that, during epidemic periods, respiratory diseases in younger children should be carefully monitored even when presenting as mild illness. We also confirm that croup is associated with influenza infection, ${ }^{33}{ }^{34}$ especially when influenza B virus is involved. Unexpectedly, ${ }^{95-37}$ we found a lower incidence of acute otitis media in influenza positive than influenza negative children. This may be related to a high incidence of respiratory syncytial virus (RSV) infection among influenza positive children, as RSV is the virus that is most frequently associated with otitis media, or might be because the frequency of acute otitis media is related to age, ${ }^{38} 39$ and the mean age of our influenza negative children was less than that of our influenza positive patients, with a significant number being aged $<3$ years; on the other hand, no other characteristic appeared different between the two groups.

In conclusion, our results demonstrate that influenza in otherwise healthy children has a significant effect on the children themselves and their household contacts. The prevention of influenza among these children may significantly reduce the number of sick subjects, the prevalence of hospitalisation, and the circulation of infection within households. Although any change in the policy of influenza vaccination requires a balanced evaluation of many aspects, our results suggest that prevention strategies should also focus on healthy children regardless of age because of their role in disease transmission.

\section{Authors' affiliations}

N Principi, S Esposito, P Marchisio, Institute of Paediatrics, University of Milan, Milan, Italy

R Gasparini, P Crovari, Department of Health Sciences, University of Genoa, Genoa, Italy 


\section{Information box}

Influenza is commonly seen as a serious illness only in the elderly and in persons with chronic conditions that place them at increased risk of complications. Consequently, influenza vaccination is recommended only in subjects more than 64 years of age and in children as well as adults with high risk medical conditions. On the basis of recent findings demonstrating the clinical importance of influenza in childhood, many health authorities now encourage influenza vaccination of healthy children younger than 2 years of age who were previously excluded from vaccination programs.

This study shows the substantial medical and socioeconomic burden of influenza on healthy children and their families. Healthy children attending day care and school are the most frequently affected by influenza and their illness is often associated with a high disease burden in families. Moreover, the results also add further information concerning the importance of influenza in paediatric practice and the clinical picture of paediatric influenza. Overall, the data suggest that prevention strategies should focus also on healthy children regardless of their age because of their role in disease transmission.

This study was supported in part by a grant from Wyeth-Lederle Vaccines, Italy.

No author has a commercial or other association that might pose a conflict of interest.

Presented in part at the 42nd Interscience Conference on Antimicrobial Agents and Chemotherapy, San Diego (CA), 27-30 September 2002, and at the 3rd World Congress of Pediatric Infectious Diseases - WSPID, Santiago (Chile), 19-23 November 2002.

In addition to the authors, the other investigators in the Flu-Flu Study Group are: C Bianchi, A Zollo, Wyeth-Lederle Vaccines, Rome; S Bosis, S Gironi, L Lambertini, R Droghetti, L Claut, Institute of Paediatrics, University of Milan, Milan; S Contos, P Durando, P Morelli, L Sticchi, I Sticchi, Department of Health Sciences, University of Genoa, Genoa; F Tancredi, L Tarallo, Paediatric Unit, Ospedale Santissima Annunziata, Naples; A Vierucci, C Azzari, Paediatric Department III, University of Florence, Florence; P Di Pietro, P Gianiorio, Gaslini Hospital, Genoa; L Bossi, E Ballerini, M Picciotti, Primary Care Paediatricians, Milan; L Carozzini, R Jamone, Primary Care Paediatricians, Genoa.

\section{REFERENCES}

1 Cox NJ, Subbarao K. Influenza. Lancet 1999:354:1277-82

2 Simonsen $L$. The global impact of influenza on morbidity and mortality. Vaccine 1999;17:S3-10.

3 Neuzil KM, Wright PF, Mitchel EF, et al. The burden of influenza illness in children with asthma and other chronic medical conditions. J Pediatr 2000;137:856-64.

4 Gasparini R, Lucioni C, Lai $P$, et al. Cost-benefit evaluation of influenza vaccination in the elderly in the Italian region of Liguria. Vaccine 2002;20:B50-4

5 American Academy of Pediatrics. Influenza. In: American Academy of Pediatrics, ed. Report of the Committee on Infectious Diseases. Red Book 2000. 25th ed. Elk Grove Village, IL: American Academy of Pediatrics, 2000:351-9

6 Izurieta HS, Thompson WW, Kramarz P, et al. Influenza and the rates of hospitalization for respiratory disease among infants and young children. $N$ Engl J Med 2000;342:232-9.

7 Neuzil KM, Mellen BG, Wright PF, et al. The effect of influenza on hospitalizations, outpatient visits, and courses of antibiotics in children. N Engl J Med 2000;342:225-31.

8 Chiu SS, Lau YL, Chan KH, Wong WHS, et al. Influenza-related hospitalizations among children in Hong Kong. N Engl J Med 2002;347:2097-103.
9 Neuzil KM, Zhu Y, Griffin MR, et al. Burden of interpandemic influenza in children younger than 5 years: a 25 -year prospective study. $J$ Infect Dis 2002; 185: 147-52.

10 Foy HM, Cooney MK, Allan I. Longitudinal studies of types A and B influenza among Seattle schoolchildren and families, 1968-1974. J Infect Dis 1976;134:362-9.

11 Fox JP, Hall CE, Cooney MK, et al. Influenza virus infections in Seattle families, 1975-1979. Study design, methods and the occurrence of infections by time and age. Am J Epidemiol 1982;116:212-27.

12 Reichert TA, Sugaya N, Fedson DS, et al. The Japanese experience with vaccinating schoolchildren against influenza. $N$ Engl J Med $2001 ; 344: 889-96$.

13 Neuzil KM, Hohlbein C, Zhu Y. Illness among schoolchildren during influenza season. Effect on school absenteeism, parental absenteeism from work, and secondary illness in families. Arch Pediatr Adolesc Med 2002;156:986-91.

14 Centers for Disease Control and Prevention. Prevention and control of influenza: recommendations of the Advisory Committee on Immunization Practices (ACIP). MMWR Morb Mortal Wkly Rep 2003;52(RR-8):1-34.

15 Hurwitz ES, Haber M, Chang A, et al. Effectiveness of influenza vaccination of day care children in reducing influenza-related morbidity among household contacts. JAMA 2000;284:1677-82.

16 Feigin RD, Cherry JD, eds. Textbook of pediatric infectious diseases, 4th ed. Philadelphia, PA: WB Saunders, 1998.

17 Meguro $\mathrm{H}$, Bryant JD, Torrence AE, et al. Canine kidney cell line for isolation of respiratory viruses. J Clin Microbiol 1979;9:175-9.

18 Zambon MC, Stockton JD, Clewley JP, et al. Contribution of influenza and respiratory syncytial virus to community cases of influenza-like illness: an observational study. Lancet 2001;358:1410-6.

19 Atmar RL, Baxter BD. Typing and subtyping clinical isolates of influenza virus using reverse transcription-polymerase chain reaction. Clin Diagn Virol 1996;7:77-84.

20 Magnard C, Valette M, Aymard M, et al. Comparison of two nested PCR, cell culture, and antigen detection for the diagnosis of upper respiratory tract infections due to influenza viruses. J Med Virol 1999;59:215-20.

21 Monto AS, Kioumehr F. The Tecumseh study of respiratory illness IX. Occurrence of influenza in the community, 1966-1971. Am J Epidemiol $1975 ; 102: 553-63$.

22 Glezen WP, Couch RB. Interpandemic influenza in the Houston area, 197476. N Engl J Med 1978;298:587-92.

23 Mullooly JP, Barker WH. Impact of type A influenza on children: a retrospective study. Am J Public Health 1982;72:1008-16.

24 Hurwitz ES, Haber M, Chang A, et al. Studies of the 1996-97 inactivated influenza vaccine among children attending day care. J Infect Dis 2000;182:1218-21

25 Cohen G, Nettleman M. Economic impact of influenza vaccination in preschool children. Pediatrics 2000;106:973-6.

26 White T, Lavoie S, Nettleman MD. Potential cost savings due to influenza vaccination of school-aged children. Pediatrics 1999;103:e73.

27 Lanari M, Giovannini M, Giuffré L, et al. Prevalence of respiratory syncytial virus infection in Italian infants hospitalized for acute lower respiratory tract infections, and association between respiratory syncytial virus infection risk factors and disease severity. Pediatr Pulmonol 2002;33:458-65.

28 Nohynek H, Eskola J, Laine E, et al. The causes of hospital-treated acute lower respiratory tract infection in children. Am J Dis Child 1991;145:618-22.

29 Boyce TG, Mellen BG, Mitchel EF Jr, et al. Rates of hospitalization for respiratory syncytial virus infection among children in Medicaid. J Pediatr 2000;137:865-70

$30 \mathrm{Kim}$ PE, Musher DM, Glezen WP, et al. Association of invasive pneumococcal disease with season, atmospheric conditions, air pollution, and the isolation of respiratory viruses. Clin Infect Dis 1996;22:100-6.

31 O'Brien KL, Walters MI, Sellman J, et al. Severe pneumococcal pneumonia in previously healthy children: the role of preceding influenza infection. Clin Infect Dis 2000;30:784-9.

32 Glezen WP, Taber $\mathrm{LH}$, Frank $\mathrm{AL}$, et al. Influenza virus infections in infants. Pediatr Infect Dis J 1997; 16:1065-8.

33 Peltola V, Ziegler T, Ruuskanen O. Influenza A and B virus infections in children. Clin Infect Dis 2003;36:299-305.

34 Peltola V, Heikkinen T, Ruuskanen $\mathrm{O}$. Clinical courses of croup caused by influenza and parainfluenza viruses. Pediatr Infect Dis J 2002;21:76-8.

35 Heikkinen T, Ruuskanen $O$, Waris $M$, et al. Influenza vaccination in the prevention of acute otitis media in children. Am J Dis Child 1991;145:445-8.

36 Clements DA, Langdon L, Bland C, et al. Influenza A vaccine decreases the incidence of otitis media in 6- to 30-month-old children in day care. Arch Pediatr Adolesc Med 1995;149:1113-37.

37 Belshe RB, Mendelman PM, Treanor J, et al. The efficacy of live attenuated, cold-adapted, trivalent, intranasal influenza virus vaccine in children. N Engl J Med 1998;338:1405-12

38 Henderson FW, Collier AM, Sanyal MA, et al. A longitudinal study of respiratory viruses and bacteria in the etiology of acute otitis media with effusion. N Engl J Med 1982;306:1377-83.

39 Heikkinen T, Thint M, Chonmaitree T. Prevalence of various respiratory viruses in the middle ear during acute otitis media. N Engl J Med 1999;340:260-4. 


\section{PostScript}

\section{LETTER}

\section{Adverse effects of rapid isotonic saline infusion}

Neville et al reported on a randomised controlled trial of hypotonic versus isotonic saline for rehydration of children with gastroenteritis. They found that isotonic saline was superior with regards to correction of hyponatraemia. The majority of patients in the study received a "rapid replacement protocol" which entailed the infusion of $40 \mathrm{ml} / \mathrm{kg}$ of isotonic saline over 4 hours in the isotonic saline arm of the study. The authors did not report on important known adverse effects associated with rapid infusion of isotonic saline which have been reported in previous randomised controlled trials of volume support with isotonic saline versus other fluids.

Rapid isotonic saline infusion predictably results in hyperchloraemic acidosis. ${ }^{2}$ The acidosis is due to a reduction in the strong anion gap by an excessive rise in plasma chloride as well as excessive renal bicarbonate elimination. ${ }^{2}$ In a randomised controlled trial with a mixed group of patients undergoing major surgery, isotonic saline infusion was compared to Hartmann's solution with $6 \%$ hetastarch and a balanced electrolyte and glucose solution. Two thirds of patients in the saline group but none in the balanced fluid group developed postoperative hyperchloraemic metabolic acidosis. ${ }^{3}$ The hyperchloraemic acidosis was associated with reduced gastric mucosal perfusion on gastric tonometry.

Another double blind randomised controlled trial of isotonic saline versus lactated Ringer's in patients undergoing aortic reconstructive surgery confirmed this result; the acidosis required interventions like bicarbonate infusion and was associated with the application of more blood products. ${ }^{4}$ Hyperchloraemia was found to have profound effects on eicosanoid release in renal tissue, leading to vasoconstriction and a reduction of the glomerular filtration rate. ${ }^{5}$ The increased eicosanoid release may also explain the findings of reduced gastric perfusion in hyperchloraemia mentioned above

The main adverse effect of saline induced hyperchloraemic acidosis, however, may be the action which is taken to correct the abnormality. Acidosis is often seen as a reflection of poor organ perfusion and poor myocardial function, and a negative base excess may prompt the application of boluses of more saline containing fluids exacerbating the acidosis, the use of blood products, escalation of inotropic support and initiation of ventilatory support. ${ }^{6}$

The safety of hyperchloraemic acidosis has not been established in prospective studies and in patients with different types of critical illness. Particularly in critically ill patients with co-morbidities like renal disease, more physiological electrolyte solutions (e.g. Ringer's lactate solution) may be preferable to isotonic saline, and a slow replacement protocol safer than rapid infusions.

M Eisenhut

Consultant Paediatrician, Luton \& Dunstable Hospital Lewsey Road, Luton LU4 ODZ, UK michael_eisenhu@@yahoo.com

doi: $10.1136 /$ adc. 2006.100123
Competing interests: none declared

\section{References}

1 Neville KA, Verge CF, Rosenberg AR, et al. sotonic is better than hypotonic saline for intravenous rehydration of children with gastroenteritis: a prospective randomised study. Arch Dis Child 2006;91:226-32

2 Prough DS, Bidani A. Hyperchloremic metabolic acidosis is a predictable consequence of intraoperative infusion of $0.9 \%$ saline. Anesthesiology 1999;90:1247-9.

3 Wilkes NJ, Woolf R, Mutch M, et al. The effects of balanced versus saline-based hetastarch and crystalloid solutions on acid-base and electrolyte status and gastric mucosal perfusion in elderly surgical patients. Anesth Analg 2001;93:811-16

4 Waters JH, Gottlieb A, Schoenwald P, et al. Norma saline versus lactated Ringer's solution for intraoperative fluid management in patients undergoing abdominal aortic aneurysm repair: an outcome study. Anesth Analg 2001 ;93:817-22.

5 Bullivant EMA, Wilcox CS, Welch WJ. Intrarena vasoconstriction during hyperchloremia: role of thromboxane. Am J Physiol 1989;256:152-7.

6 Brill SA, Stewart TR, Brundage SI, et al. Base deficit does not predict mortality when secondary to hyperchloremic acidosis. Shock 2002; 17:459-62.

\section{BOOK REVIEW}

\section{Weight matters for children}

Edited by Rachel Pryke. Oxon: Radcliffe Medical Press Ltd, 2006, £14.95 (US\$28 (approx.); $€ 22$ (approx.)l, paperback, pp 215, ISBN 1857757718

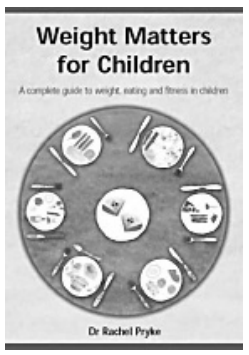

It seems impossible to open a newspaper or turn on the television without the issue of childhood obesity being raised. The government has set targets to reduce the incidence of childhood obesity and school based programmes have been estab-

lished, and yet the number of children who are obese continues to rise. What seems to be lacking and what this book sets out to provide is specific practical guidance for parents to follow as to what families need to be doing on a day to day basis to ensure children remain healthy and avoid becoming obese.

The primary focus is on parents and carers, and the author, who is a GP, frequently draws on her own experience as a mother to give examples of her own family life, which helps give credence to the messages which run throughout the book. The issue of choice is dealt with very well and discusses how important it is to give children choice and how parents can influence children to make the right choice. Parents are also encouraged to examine their own parenting styles to see how this influences the behaviour and eating habits of their children.
There are separate sections on preschool children and junior children, covering topics ranging from breast feeding and weaning to explanations about what constitutes a healthy diet. The advice about managing behavioural difficulties around mealtimes is particularly helpful, with sections such as "Tips to avoid becoming wound up at meal times" providing plenty of practical suggestions for families to try. There are also practical suggestions on encouraging physical activity in children and reducing television watching. The issue of dealing with a child who is already overweight is addressed, emphasising the need to take action early, placing this responsibility within the family context. There is also helpful information about understanding children's psychological wellbeing, examining the issue of low self esteem, bullying, and depression.

The final section covers nutrition and health problems. Basic nutritional information is provided to help make sense of the contents of our food and details what should constitute a healthy well balanced diet. There is a well written section on a wide variety of medical problems encountered which may affect a child's growth, ranging from cows' milk allergy to cystic fibrosis, and sources of further information are well referenced.

Overall I felt that this was a well written book, packed full with helpful practical suggestions. As a paediatrician, the advice contained within the chapters covered many of the food related problems seen in clinic. As a parent I also recognised many of the scenarios and remembered many meal times with young toddlers which were far from enjoyable! My one criticism of the book would be the general layout as I felt this was more in keeping with a medical textbook rather than a manual for parents. I'm not sure whether first impressions of the book would encourage parents to pick it up. However, this certainly won't deter me from recommending this book. I do feel this will be of benefit to all paediatricians to read as well as GPs, health visitors, school nurses, and of course also parents, especially those dealing with truculent toddlers!

C Grayson

\section{CORRECTIONS}

doi: 10.1136/adc.2003.045401corr 1

Principi N, Esposito S, Gasparini R, Marchisio P, Crovari P, for the Flu-Flu Study Group. Burden of influenza in healthy children and their households. Arch Dis Child 2004;89: 1002-7.

This article has been retracted by the publisher because of significant overlap with Principi N, Esposito S, Marchisio P, Gasparini $\mathrm{R}$, Crovari P. Socioeconomic impact of influenza on healthy children and their families. Pediatr Infect Dis J 2003;22(Suppl 10):S207-10.

doi: 10.1136/adc.2005.77065corr 1

D M B Hall and M J Renfrew. Tongue tie (Arch Dis Child 2005;90:1211-5).

Photographs 1, 2, 4, and 5 in this article are reproduced by kind permission of Kay Hoover, MEd, IBCLC. 